Marija Uršula Geršak

UDK 81'255.4=134.2=163.6:378(497.4)

Filozofska fakulteta, Univerza v Ljubljani

Slovenija

ursa.gersak@ff.uni-lj.si

\section{Maja Šabec}

Filozofska fakulteta, Univerza v Ljubljani

Slovenija

maja.sabec@ff.uni-lj.si
DOI: $10.4312 /$ vestnik.13.553-570

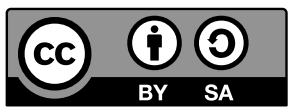

\title{
SODELOVALNO UČENJE PRI POUKU PREVAJANJA NA PRIMERU ANTOLOGIJE PARAGVAJSKIH PRAVLJIC ${ }^{1}$
}

Živimo v čedalje kompleksnejših družbah. V zadnjih desetletjih smo priče neslutenemu in hitremu tehnološkemu napredku in napredku znanosti, ki ju zaznamujeta teoretični pluralizem in kriza obstoječih paradigem. Priče pa smo tudi krizi reprezentativnih demokracij v zahodnih družbah, uničevanju okolja in posledicam podnebnih sprememb, novim boleznim, čedalje večji neenakosti na lokalni in globalni ravni ter masovnim migracijam zaradi vojn, podnebnih sprememb, revščine in ambicij kapitala.

Šolske politike bi morale odločneje odgovoriti na te izzive. Šola se čedalje bolj oddaljuje od življenja, rezultati raziskovanj učenja in poučevanja pa od prakse, ki ne odseva novih spoznanj (Aberšek, Flogie, Šverc 2015: 22): osredotočeni smo na poučevanje, in ne na učenje; še vedno je poudarek na individualnem in tekmovalnem učenju, in ne na sodelovalnem učenju, ki poleg kognitivnih procesov upošteva čustva in motivacijo ter gradi tudi socialne kompetence in védenja; malo časa je namenjenega participaciji učečega se in njegovi aktivni vlogi; znanost je prevečkrat predstavljena kot zaprt sistem dokončnih pojmov, ki jih učitelj ponavlja; vztrajamo na razvoju logičnega mišljenja; ločujemo nedeljivo enotnost razmišljanja, čutenja in delovanja/ukrepanja; malo pozornosti posvečamo odgovornosti in angažiranju učečih se za lastno učenje (Ferreiro Gravié, Espino Calderón 2001: 20). Johnson in Johnson (2018: 60) opozarjata, da je pri pasivno strukturiranih učnih izkušnjah študent pasiven, posluša učitelja, si zapisuje, je tiho in vodijo ga drugi. Aktiven študent pa konstruira znanje, odkriva, spreminja lastno védenje in znanje,

1 Raziskava je bila izpeljana v okviru raziskovalnega programa P6-0218 - Teoretične in aplikativne raziskave jezikov: kontrastivni, sinhroni in diahroni vidiki, ki ga financira ARRS. 
kognitivno in čustveno deluje in sodeluje $\mathrm{z}$ drugimi študenti in $\mathrm{z}$ učnim gradivom. Zato »znanja in spretnosti, ki so bila temelj napredka v 19. in 20. stoletju, v sodobnem svetu (21. stoletju) več niso zadostna«, treba je uvajati nove veščine in kompetence in umestiti sodobne tehnologije v proces učenja (Aberšek, Flogie, Šverc 2015: 14).

Učitelji prevajanja na katedrah za španski jezik in književnost Filozofske fakultete Univerze v Ljubljani v prizadevanjih za učinkovitejši, uspešnejši in bolj interaktiven študijski proces namenjamo več prostora neposrednemu učenju, učenju učenja $z$ uporabo različnih metod, učenju z razumevanjem, ki pomeni aktivno znanje in prenos naučenega v nove situacije, ter hkrati krepi solidarnost, odgovornost, strpnost, sporazumevanje in soodločanje. Da bi dosegli navedene cilje in se lotili učenja in poučevanja celostno, so se kot najprimernejše izkazale različne oblike sodelovalnega učenja. Tudi zato, ker je dokazano, kot piše Slavin, da je metoda sodelovalnega učenja »med najbolj evalviranimi alternativami tradicionalnemu poučevanju, ki so danes v uporabi« in da »sodelovalno učenje ponuja praktične možnosti za oblikovanje zanimivega in sodelovalnega učnega okolja, ki učencem pomaga pri obvladovanju tradicionalnih veščin in znanja, pa tudi pri razvoju ustvarjalnih in interaktivnih veščin, ki so potrebne v današnji družbi in gospodarstvu « (Slavin 2013: 155, 158). Tudi Rot Vrhovec (2015: 157) navaja raziskave, ki ugotavljajo, da s sodelovanjem izboljšujemo odnose, psihično zdravje in učno uspešnost. Dodamo lahko še boljše delovno vzdušje, razvoj empatije, strpnosti, boljšo samopodobo posameznika itd. Brata Johnson sta s številnimi raziskavami dokazala, da sodelovanje spodbuja »več sklepanja na višji ravni, pogostejše ustvarjanje novih zamisli in rešitev in večji prenos naučenega iz ene situacije v drugo « (Johnson, Johnson 2017: 7). ${ }^{2}$ Slavin (2013: 159) pa hkrati opozarja, da kljub tridesetim letom raziskovanja sodelovalnega učenja to še vedno ostaja na robu šolskih politik.

Prispevek predstavlja sodelovalno učenje pri pouku prevajanja in poskus nadgraditve omenjene metode. Osredotoča se na analizo dela v sodelovalnih učnih skupinah, opis procesa in ugotovitve, ki temeljijo na praktičnem delu. Na podlagi literature, ki ga metodološko uokvirja in ki sva jo uporabili pri snovanju in aplikaciji različnih oblik sodelovalnega učenja $\mathrm{v}$ učnem okolju, na konkretnem primeru ponazarja prenos glavnih teoretičnih izhodišč na specifično skupino in nalogo oziroma cilj učenja. Proces dela ilustrirajo tudi izbrane naloge in razmišljana študentk in študenta, ${ }^{3}$ ki so v njem sodelovali. ${ }^{4}$

\footnotetext{
2 Prevodi navedkov iz španščine in angleščine so najini.

3 V nadaljevanju je uporabljena moška slovnična oblika.

4 Študenti so navedeni anonimno: $\breve{S} 1, \breve{S} 2$ itn., pri prevajanju pa so sodelovali por abecednem vrstnem redu študentke in študent Eva Balantič, Sandra Balić, Valerija Bončina, Alexander Centa, Mojca Ficko, Zala Kerec, Anamarija Kočevar, Nina Kraševec, Jesika Kustec, Rasmira Majetić, Ines Metličar, Svetlana Pavlin, Urška Perhavec, Urška Ukmar, Cita Vidmar, Iva Vogrič, Lana Volk, Vanesa Zaman, Ana Zelenko, Saranda Zogaj, Ana Žlof.
} 
V prvi polovici 20. stoletja so se na področju izobraževanja pojavile številne teorije, psihopedagoške paradigme, ki poskušajo odgovoriti na izzive sodobnih družb. Na izobraževalne sisteme in pedagoško prakso je vplivala in vpliva tudi kognitivna znanost, ki je v zadnjih desetletjih dosegla nesluten razvoj. Odgovorov na vprašanja, kako mislimo, se učimo, kje se skrivajo čustva, se loteva transdisciplinarno: vključuje nevroznanost, psihologijo, filozofijo, jezikoslovje, družbene vede, umetno inteligenco, kibernetiko itn. (Aberšek, Flogie, Šverc 2015: 43-45).

Kot teoretično izhodišče sodelovalnega učenja velja omeniti še socialni konstruktivizem, ki prav tako združuje različne teorije: psihogenetsko teorijo Jeana Piageta, teorijo kognitivnih shem, sociokulturno psihologijo Leva Vigotskega, humanizem, na področju pedagogije pa zlasti teorijo aktivne šole, kritično didaktiko, Deweyevo teorijo in pedagogijo Paula Freira (Ferreiro Gravié 2003: 32). Kot pravi Ferreiro Gravié, gre za izgradnjo znanja in osebnosti učečih se, medtem ko pomeni graditi znanje razumeti bistvo nečesa, ozavestiti, kaj vemo, kako razmišljamo, čustvujemo, znati strukturirati in organizirati informacije in čustva. Razumevanja pa ne moreš doseči sam, potrebuješ drugega, in učeči se je v odnosu do kulturnega, socialnega konteksta, v katerem se nahaja. Zato so tako pomembne oblike dela, kot so dialog, spraševanje, soočanje mnenj, različni pogledi na določen problem, argumentacija itn.

Johnson, Johnson in Holubec (1999: 4) trdijo, da lahko s sodelovalnim učenjem dosežemo tri glavne cilje: večjo uspešnost vseh članov sodelovalne skupine; pozitivne medsebojne odnose, ki spodbujajo vrednotenje različnosti; učencem zagotovimo izkušnje, ki jih potrebujejo za dosego zdravega socialnega, psihološkega in kognitivnega razvoja. Tratnik pa definira sodelovalno učenje tako:

Sodelovalno učenje je ena izmed oblik učenja, ki poleg kognitivnih procesov poudarja socialni vidik učenja, saj ceni hkratno sodelovanje vseh učencev v razredu. Učenci preko razmisleka, delovanja, odkrivanja in reševanja nalog aktivno izgrajujejo svoje znanje ter hkrati razvijajo komunikacijske, sodelovalne in socialne veščine. Če želijo doseči zastavljeni cilj, morajo pozitivno sodelovati s sošolci, si izmenjati ideje, razmišljanja, vprašanja in odgovore. Svoje znanje lahko primerjajo z drugimi, ga dopolnijo in utrdijo (Tratnik 2014: 21).

Ta metoda je zanimiva tudi zato, ker je podlaga za druge oblike sodelovanja, kot so aktivno učenje, timsko delo, projektno, tudi problemsko učenje. Elemente vseh teh oblik je vsebovala tudi izvedba obravnavanega prevajalskega projekta.

Sodelovalno učenje je, s strnjeno definicijo, oblika učenja v majhnih skupinah, $v$ katerih študenti poskušajo doseči zastavljeni cilj, in z uporabo različnih sodelovalnih metod (struktur) (Strokovna podlaga ... 2020). Najpomembnejše pri tej metodi dela je, 
da si učeči se prizadevajo za skupno dobrobit, konstruktivno izmenjavo mnenj, kritično presojo, reševanje problemov. Uspeh posameznika je odvisen od uspeha celotne skupine in obratno. Sodelovalno učenje se razlikuje od tradicionalnega v učni interakciji med študenti na kognitivni, čustveni, metakognitivni in socialni ravni (Strokovna podlaga ... 2020; Aberšek, Flogie, Šverc 2015: 35).

Drugačna je tudi vloga učitelja - je opazovalec in posrednik. Posreduje le, ko je potrebno, z razlago, vprašanjem, napotkom, kaj je treba popraviti, virom, v katerem lahko učeči se najde informacijo, če tega ne naredi sam. Problemov ne rešuje, njegova naloga je ustvariti sodelovalno vzdušje, ki vodi k pozitivni soodvisnosti in povezanosti, ter spodbujati avtonomijo učečega se in skupine. Fokus ni na učitelju ali učečem se, temveč na odnosu, interakciji med enakimi (Ferreiro Gravié, Espino Calderón 2001: 62). Gre torej za recipročnost med učečim se, sodelovalno učno skupino in učiteljem. Pri našem projektu sva bili profesorici dve, torej je recipročnost potekala tudi med nama in študenti so jo lahko opazovali in komentirali. Učitelj mora učeče se vseskozi spodbujati, da so zmožni doseči cilj, in jim s tem tudi izkazati spoštovanje. To ne pomeni, da jim ne sme pomagati, a še pomembnejše je dopustiti napako in s tem omogočiti samokorekcijo. Spoštovati je treba tudi način in ritem dela posameznikov in skupine.

Raziskovalci sodelovalnega učenja se strinjajo, da je to lahko uspešno le, če vključuje pet bistvenih elementov: pozitivno soodvisnost, individualno in skupinsko odgovornost, spodbujanje neposredne interakcije, socialne veščine in skupinsko evalvacijo (Casanova 2010: 54; Johnson, Johnson, Holubec 1999: 9-10). Našteta načela so nama služila kot vodilo pri obravnavanem procesu prevajanja antologije paragvajskih pravljic.

\subsection{Predstavitev projekta (situacije)}

V akademskem letu 2020/21 smo se na katedrah za španski jezik in književnost Filozofske fakultete Univerze v Ljubljani odzvali na ponujeno priložnost in sprejeli izziv, da prevedemo $\mathrm{v}$ slovenščino antologijo sodobnih paragvajskih pravljic in jo pripravimo za knjižno izdajo. To je bil torej cilj (naloga) vseh sodelujočih. Projekt je bil načrtovan, strukturiran in je potekal v okviru formalnega učnega procesa pri predmetu Prevajanje, a je presegel število predvidenih kontaktnih ur, saj je bil obsežen, dolgotrajen (okoli pet mesecev) in je zahteval veliko napora celotne sodelovalne učne skupine. ${ }^{5}$ Sodelovali so enaindvajset študentov magistrskega programa Hispanistika, dve profesorici mentorici

5 Predmet, pri katerem se študenti učijo (literarno) prevajanje iz španščine v slovenščino in iz slovenščine v španščino, sicer obsega 60 ur, 30 ur seminarja in 20 ur vaj. Za projekt je bilo glede na organizacijski načrt razpoložljivih 15 ur seminarja. 
in založba Malinc, ki je antologijo letos tudi izdala. ${ }^{6}$ Študenti so aktivno sodelovali v procesu nastajanja knjige, od sprejetja naročila prevoda do izdaje in tudi pri promociji. ${ }^{7}$ Sestavili so še glosar manj znanih besed z razlago ter prevedli in oblikovali biografije avtorjev pravljic.

Nikakor ni zanemarljivo, da smo delali v izrednih, »korona razmerah«. To pomeni, da sta razen dveh uvodnih srečanj ves proces in komunikacija potekala prek spleta, na daljavo (po zoomu) ter po elektronski pošti in prek komentarjev, ki smo jih s programom »sledi spremembam« vnašali v skupni dokument prevedenega besedila. S temi tehničnimi pomagali se je v drugačni obliki od običajnega dela v predavalnici zagotovila dialoškost. Na koncu procesa smo se v neformalnem pogovoru strinjali, da nam je intenzivno skupnostno, sodelovalno delo tudi pomagalo preživeti težko obdobje dolgotrajnega zaprtja fakultete in pomanjkanja dejanskih socialnih stikov in nam omogočilo, da smo se intenzivneje posvetili nalogi.

Š1: Delo je potekalo zelo drugače, kot bi v normalnih okoliščinah. Dobili smo se v živo dvakrat, ko smo organizirali delo. Prevajali pa smo doma in razpravljali na daljavo. Bili smo sicer že vajeni, saj smo tako delali že pol leta, in smo vedeli, da lahko uspemo tudi na ta način. Prednost je bila, da smo se najprej povezali v pare, ker je na daljavo [tako] lažje komentirati. Nato v skupine po štiri in šele nato vsi skupaj, celotna skupina, ko smo vsi pisali in vse pregledovali, takrat smo delali pa bolj pisno. Ustno smo razpravljali bolj o podrobnostih. ${ }^{8}$

\subsection{Priprava, oblikovanje skupin, način in postopek dela, evalvacija}

Prevajanje velja za samotarsko delo, le občasno poteka v paru ali manjši skupini, na primer pri učenju prevajanja ali na prevajalskih delavnicah. Zato je bila naloga, prevesti literarno antologijo v skupini kar 21 študentov in dveh profesoric, velik izziv in hkrati vzrok za pomisleke. Kako zagotoviti sodelovanje, odgovornost, pozitivno interakcijo vseh? Nam bo uspelo prevesti do določenega roka, saj sodelovalna metoda, sploh pri tako

6 Knjižna izdaja antologije je del širšega bilateralnega sodelovanja med Slovenijo in Paragvajem. Leta 2020 je minilo sto let od rojstva pomembne slovenske antropologinje dr. Branislave Sušnik, ki je vse življenje delovala v Paragvaju. Na nacionalni ravni so potekali številni dogodki v počastitev te obletnice. Ministrstvo za zunanje zadeve Republike Slovenije je v sodelovanju s paragvajskim veleposlaništvom na Dunaju ob tej priložnosti katedrama za španski jezik in književnost na Oddelku za romanske jezike in književnosti predlagalo sodelovanje pri prevodu izbora pravljic desetih sodobnih paragvajskih avtorjev, hkrati pa je v Paragvaju izšla antologija slovenskih pravljic v paragvajski španščini. Tudi pri prevodu ene od teh pravljic sta sodelovali dve študentki španskega jezika in književnosti. 7 Skupinsko prevajanje s študenti za dejanskega naročnika je na magistrskem programu Hispanistika utečena praksa. Objavljenih je bilo že več prevedenih knjig in dramskih besedil, dve sta bili tudi uprizorjeni.

8 Razmišljanja študentov, ki jih navajava v prispevku, so del razprave na okrogli mizi, na kateri smo predstavili svojo izkušnjo. Organizirala jo je založba Malinc in je dostopna na njeni YouTube strani. Tukaj sva jih povzeli in preoblikovali za pisno objavo. 
velikem številu sodelujočih, zahteva čas? Bo slog antologije dovolj enoten, da za bralca ne bo moteč? Bodo študenti dovolj motivirani, da bodo prevzeli odgovornost in vztrajali? Je to za nas prevelik zalogaj? Kako bo potekal dialog, soočanje mnenj, argumentacija, kritično razmišljanje na daljavo, brez osebnega stika?

Tudi učitelj je navajen v glavnem delati »sam«. Ima svoje učence, predavalnico, knjigo, največkrat ne vpraša za pomoč ali podporo učencev, pogosto tudi ne kolegov. $\mathrm{V}$ tem primeru pa sva mentorici ves čas usklajevali na eni strani sodelovanje med nama in na drugi s skupino ali posamezniki. Morda je bila to dodana vrednost, saj so študenti lahko razpravljali med sabo in s profesoricama ter hkrati opazovali diskusijo med njima.

Na uvodni uri sva študentom predstavili zamisel o skupinskem prevajanju ter skupni cilj - knjižno izdajo prevedenih besedil - in predvideni način dela za njegovo dosego.

Študenti so se najprej sami razdelili v dvojice, v eni sodelovalni učni skupini pa so bile tri članice. Nekateri sodelujoči so se poznali, v preteklosti že delali skupaj, celo pri podobni izkušnji prevajanja, nekateri pa so se spoznali šele pri tem predmetu. Dvojice so bile heterogene glede znanja španščine, prevajalskih veščin in starosti. Vsaka je bila zadolžena za prevod ene pravljice (ali dveh krajših). Vsa besedila so dobili vnaprej in so si lahko izbrali, katero bodo prevajali. Po razdelitvi v skupine sta bili dve uri posvečeni pogovoru in organizaciji dela. Urednica z založbe Malinc, specializirane za otroško in mladinsko književnost, je na uvodnem predavanju o mladinski književnosti opozorila na posebnosti prevajanja za mlade bralce in otroke in ovrgla zmotno predstavo o enostavnosti te literarne zvrsti.

Š3: Na začetku smo rekli, ah, saj gre za pravljice, to ni zahtevno, potem pa ugotoviš, da je veliko stvari, na katere moraš biti še bolj pozoren; na primer, da morajo biti besede razumljive mlajšim. Je bil izziv, pomaga, če poznaš otroško literaturo, ti je besedišče bliže. Pa še to, v različni delih Slovenije se, na primer - primer, ki sva ga imeli s kolegico - igra skrivalnic imenuje in igra drugače, in kaj uporabiti: se pofočkati ali kaj drugega?

Naslednji korak je bil prvi, »grobi« prevod pravljic. Najprej ga je naredil vsak sam, potem v dvojici s kolegom. Mentorici sva vsak prevod pregledali in druga za drugo zapisovali pripombe, vprašanja, pohvale in pomisleke v »oblačke« v besedilu. Dvojica je sprejela ali zavrnila predloge in besedilo izpilila. Nato sva se z vsako dvojico srečali prek zooma, da smo predebatirali odprta vprašanja, opozorili sva na napake pri rabi maternega jezika, morebitno nerazumevanje izvirnika in podobno. Vsi sodelujoči smo morali argumentirati, kritično presoditi, se uskladiti. Če je bilo treba, sva jim svetovali, kaj naj dodatno preverijo, in jih tudi seznanili z najinim iskanjem informacij. 
Odlomek pisnega dialoga mentoric s študenti: ${ }^{9}$

Delovni prevod: Ko se je sprehajal po čudoviti aveniji, obkroženi s kokosovimi palmami, so se mu približale prodajalke čip/chip in aloje/alohe, ki so na ves glas ponujale svoje izdelke.

Komentarji k delom prevoda:

- po čudoviti aveniji

P1: lepi/prelepi

- čip/chip in aloje/alohe

P2: Sirovih štručk / slanega peciva in ledenega čaja. Še ve raziščite malo. Ali bomo pustili izvirno besedo?

P1: Preverite, kako se sklanja chipa (m.)

- aloje/alohe

P1: To je pa res problem: načeloma se zapis, če ne gre za uveljavljeno, torej poslovenjeno besedo, ohrani v izvirniku, torej bi moralo biti aloja, ampak to se v slovenščini prekriva s slovenskim imenom rastline aloya.

- izdelki

P1: Verjetno ste se - upravičeno - hotele izogniti besedi blago. Ampak chipa je še izdelek, aloja pa ne.

Kaj pa proizvodi? Preverite v SSKJ.

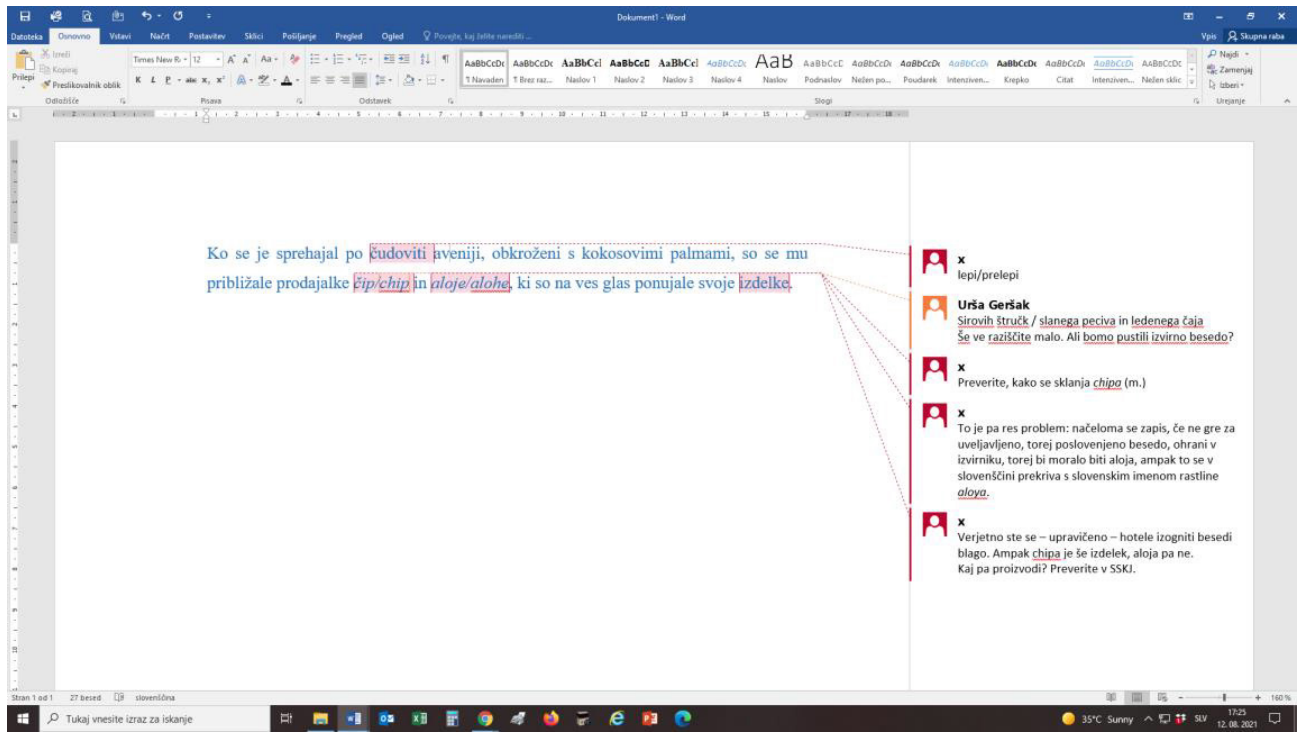

Slika 1: Posnetek zaslona z besedilom in komentarji mentoric.

9 Profesorica $1(\mathrm{P} 1)$, profesorica $2(\mathrm{P} 2)$. 
Pogovarjali se nismo samo o odločitvah, jezikovnih težavah, temveč tudi o izkušnji novega načina dela. Komentiranje oziroma pregledovanje in popravljanje prevajanja je nehvaležno, saj pri prevajanju v mnogih primerih ni absolutne rešitve, lahko je več enakovrednih predlogov, zato sva po najinih prvih pripombah študentom $\mathrm{v}$ elektronskem sporočilu pojasnili najino vlogo in jih tudi vprašali, kako so sprejeli takšno količino predlogov in popravkov:

Kakšen učinek so imeli na vas »popravki«, kako ste jih razumeli, sva vas spodbudili, prestrašili, poklopili? Ste onemeli? Iskreno, povejte, ko ste odprli dokument, kako ste se počutili?

Š1: Pričakovala sem pripombe, smo v procesu popravljanja, nastajanja besedila, sem pričakovala še več pripomb.

Prevode so nato prebrali in komentirali študenti med sabo: po dve dvojici sta se povezali v skupino štirih, vsaka dvojica je prebrala pravljice druge, zapisala komentarje naravnost $\mathrm{v}$ prevod, prva dvojica pa je komentarje proučila in jih upoštevala ali ne. Odprta vprašanja, diskusija in usklajevanje so nato tako kot prvič z mentoricama potekali še »v živo«. V veliko situacijah sva sodelovali kot članici skupine, komentarje sva dopolnjevali z mnenji ali vprašanji. Takšna dinamika je pomenila, da je bilo treba nenehno argumentirati in sprejemati predloge, kritike in pohvale drugih, s tem pa sta se krepili samopodoba učečega se in njegova motivacija za študij, lastnosti, ki so ju kot pozitivne rezultate sodelovalnega učenja potrdile v uvodu omenjene raziskave.

Odlomek pisnega dialoga med študenti:

Prevod: Po končani zabavi se je Malena namenila pospraviti darila. Bila je koketna, a tudi skrbna deklica. Tedaj je iz kota sobe zaslišala pridušeno čivkanje. Radovedno je preiskala vsak del, a ni ugotovila, od kod prihaja to tako usmiljenja vredno petje.

Komentarji k delom prevoda:

- Po končani zabavi

Š9: Kaj pa morda: Ko se je zabava končala?

- Bila je koketna

Š10: Se mi zdi, da je to malo preveč specifična beseda za otroke, pa tudi Malena ni pretirano spogledljiva.

Š9: To mi nekako ne zdi primerno za malo punčko; našla sem, da lahko pomeni tudi 'prijetna' (encantadora) ali čedna, ljubka.

Š10: Mogoče tudi »spogledljiva«?

- pridušeno čivkanje

Š10: Mogoče tudi »pritajeno«?

- pridušeno čivkanje 
Š10: Lepo!

- Radovedno je preiskala vsak del

Š1: Tukaj mi manjka - vsak del česa? Verjetno sobe? Ali kota sobe? Mi bi rekli, da je preiskala vsak kot/kotiček, ampak tukaj imamo kot že prej, tako da to ne gre.

Morda pa: Radovedno je vse preiskala, a ni ugotovila...

- od kod prihaja to tako usmiljenja vredno petje

Š9: Tudi »otožno«; sicer ne vem, če je isti pomen. Sicer pa bi izpustila »tako«, se lažje bere.

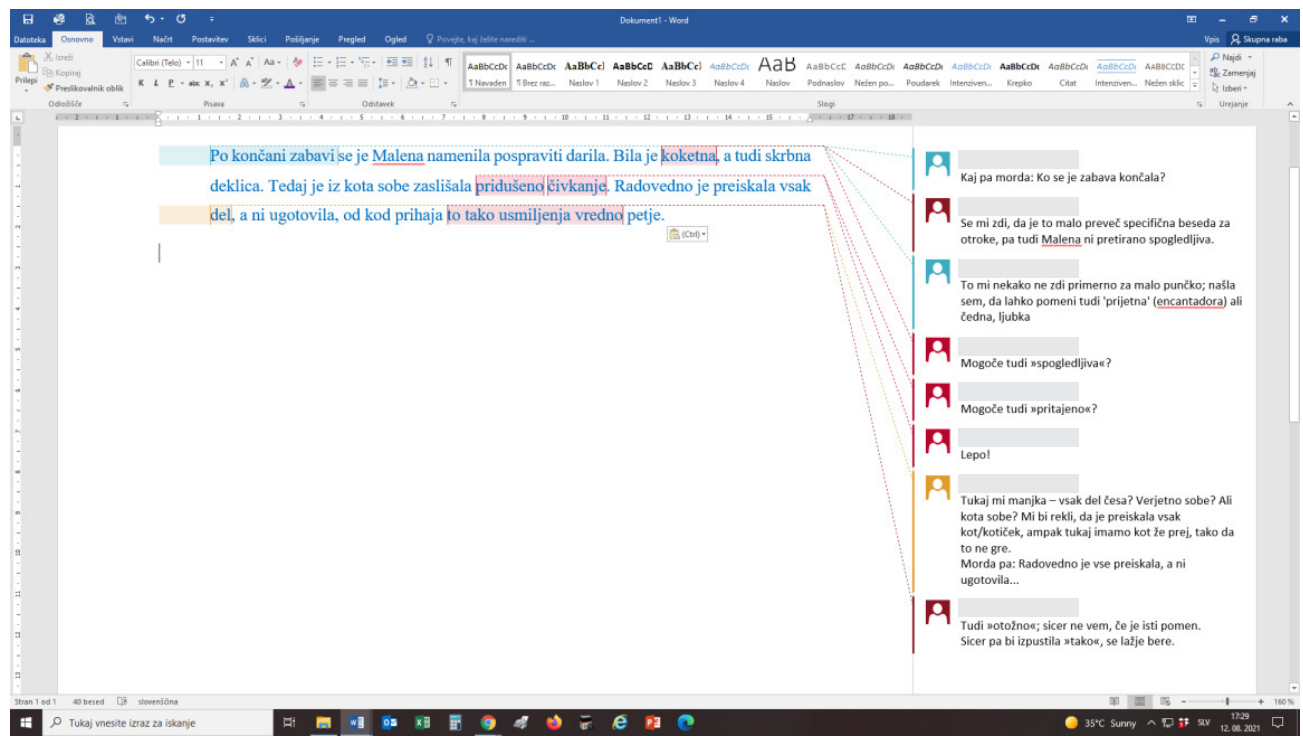

Slika 2: Posnetek zaslona z besedilom in komentarji študentov.

Prevod paragvajskih pravljic se je izkazal kot dobra naloga prav za sodelovalno učenje. Poleg tega, da so se študenti učili prevajalskih tehnik, strategij, popravljanja napak pri razumevanju in rabi maternega in tujega jezika, so prevajali sodobna besedila paragvajske književnosti, ki je v slovenskem prostoru malo poznana, tako kot je malo poznana ta južnoameriška država. To pomeni, da smo se skupaj učili tudi o Paragvaju, paragvajski družbi, kulturi in zgodovini. Soočali smo se s posebnostmi paragvajske španščine, ki se razlikuje od evropske, z nepoznanimi rastlinami in živalmi, prevedki njihovih imen in sistemskimi prevajalskimi rešitvami: posloveniti izraz ali ga ohraniti v izvirniku in zapisati ležeče; kaj narediti s kulturnimi, političnimi pojmi, ki so pri nas malo poznani ali nepoznani? Študenti so ob delu sestavljali seznam odprtih težav, rešitve smo iskali skupaj, se posvetovali in usklajevali. Hkrati je nastajal tudi seznam manj znanih pojmov, ki so bili nato vključeni v glosar na koncu knjige. Nekajkrat smo poiskali jezikovno 
pomoč pri paragvajskih strokovnjakih, pri prevodu nekaterih drevesnih vrst pa na primer pri profesorju na Fakulteti za gozdarstvo. Naloga, ki smo si jo zadali, je bila večplastna in kompleksna.

Š2: Najbolj nov je bil stik s paragvajsko literaturo. Zelo zanimiv vidik, nam študentom, skozi pravljice spoznavali drugo plat Paragvaja, ki nam prej morda ni bila poznana, spoznavanje države skozi literaturo, na en tak fascinanten način spoznavanja države, ne skozi neke objektivne podatke o državi, prebivalcih, gospodarstvu, okolju, pač pa Paragvaja skozi oči Paragvajcev, izkušnja, ki je nova vsem nam. Tudi če smo prej kaj brali, to je drugače, pridobili smo bolj poglobljen pogled na Paragvaj in družbo.

Š7: Ta predmet sem si predstavljala kot dolgotrajen proces in si ponosen, ko vidiš svoj tekst $\mathrm{v}$ knjigi in tudi lahko res ugotoviš, ali se $\mathrm{v}$ prihodnosti vidiš na prevajalski poti, eni v tem bolj uživajo, drugi manj. Sam proces je bil dolg, a sta profesorici zelo pomagali, sploh pri moji pravljici so bile besede, katerih prevedkov še nimamo v slovenščini, na primer lapacho, in nismo vedeli, kaj naj naredimo. Dodali smo slovarček besed, v katerem se lahko tudi bralci kaj novega naučijo. Pa moram tudi povedati, da so te pravljice nekaj čisto novega, ko sem jaz bila mlada, nismo brali takih pravljic, v nekaterih sem zasledila kritičen ton, okoljske probleme, ene so nadrealistične, zelo so različne.

Na koncu smo vsi prebrali vse pravljice in vnesli zadnje pripombe. Sledilo je ponovno pregledovanje, soočanje mnenj in usklajevanje skupne različice prevoda oz. prevodov.

Vsi sodelujoči s(m)o bili aktivno vključeni tudi pri vseh nadaljnjih korakih priprave knjige na izid. Prevod je najprej pregledal lektor, označil je popravke, sistemsko poenotil nekatere jezikovne in slogovne neenakosti in vnesel dragocene predloge za izboljšave. Tako se je oblikovala končna različica prevoda, ki smo jo oddali založbi. Urednica je sporočila še nekaj popravkov in tehničnih uskladitev. Študente je povabila k sodelovanju pri izbiri naslovnice. Korekturo (prvo in drugo) smo naredili vsi sodelujoči. Knjiga je izšla. Zastavljeni cilj je bil izpolnjen.

\subsection{Elementi sodelovalnega učenja v procesu prevajanja}

V procesu izvedbe projekta sodelovalna metoda ni bila edina, so pa na njej temeljile vse druge metode in oblike učenja, tako tiste, ki poudarjajo participacijo učečega se, njegovo aktivno delovanje in skupinsko delo, kot tiste bolj tradicionalne, na primer pojasnjevanje ali razlaga. S smiselno kombinacijo je bil dosežen cilj aktivnega učenja in angažiranosti študentov. 
Zasnova projekta prevoda antologije pravljic, njegov proces in rezultat dokazujejo, da izpolnjujejo vseh pet elementov sodelovalnega učenja (Casanova 2010: 54; Johnson, Johnson, Holubec 1999: 9-10).

\section{Pozitivna povezanost/soodvisnost}

Pozitivna povezanost je nujna za sodelovanje. Najbolje jo ponazarja že zapisana maksima, da je posamezni član skupine lahko uspešen le, če so uspešni vsi člani skupine oziroma vsi dosežejo skupni cilj (Johnson, Johnson, 2017: 3). Cilj naloge je bila izdaja knjige. Že sama naloga je delno zahtevala povezanost in soodvisnost in to je olajšalo ustvarjanje pozitivne povezanosti, hkrati pa je pozitivno vplivalo na motiviranost, saj je izdaja knjige pomenila konkreten cilj, ki presega okvire izobraževalnega sistema. Pozitivna povezanost se je stopnjevala s širjenjem sodelovalnih skupin z dveh na štiri člane in nato na celo skupino. Ferreiro Gravié (2003) ugotavlja, da pozitivna povezanost prinese študentom vzore, ki jih lahko posnemajo. Imajo možnost delovati, povedati, čutiti, pomagati. Pričakovanja so lahko večja (več glav več ve), soočajo različne poglede na določeno temo, problem itn. "Za tovrstno sodelovanje potrebujejo komunikacijske in sodelovalne veščine, ki predstavljajo svojevrsten prispevek k socializaciji učencev« (Tratnik 2014: 20).

V skupini študentov-prevajalcev se je razvila pozitivna povezanost in soodvisnost. Delo sva opazovali in preverjali predvsem z dialogom na skupnih srečanjih. Pozitivno naju je presenetilo dvoje: pogostejše sodelovanje študentov, ki navadno (v prejšnjih letih, pri drugih predmetih) niso bili tako dejavni, in velika odgovornost in angažiranost prav vseh sodelujočih. Tudi zaradi pozitivnega vzdušja v skupini so vse naloge opravili dobro in pravočasno. Komentarji, ki so jih zapisovali v prevode kolegov - pripombe, predlogi, opozorila, pohvale -, dokazujejo, da so si informacije delili, zastavljali vprašanja, samostojno razmišljali, se pohvalili, pomagali in se spodbujali. Skupaj so iskali vire pri reševanju zagat. V spodnjem primeru ena od dvojic izraža dvom glede določenega pojma, ki ga bo treba razložiti v glosarju. Naveden je tudi vir, kje sta razlago iskala.

\section{- $\quad$ cocido (quemado) oz. mate čaj}

Lahko bi šlo za paragvajski način priprave čaja mate, ki vključuje žganje, vendar se v izvirniku pojavi samo cocido, pri čemer ne vemo, ali gre za v pogovornem jeziku skrajšani izraz cocido quemado ali preprosto za čaj mate na bolj znani, argentinski način (brez prižiganja listov in sladkorja), ki bi se dejansko imenoval samo cocido.

https://es.wikipedia.org/wiki/Mate_cocido\#cite_note-9, https://www.tembiuparaguay.com/recetas/cocido-quemado/ 


\section{Individualna in skupinska odgovornost}

Vsak sodelujoči je osebno odgovoren za izvedbo posameznih nalog, hkrati pa tudi za rezultat vseh, kajti s svojo dejavnostjo pripomore k doseganju skupnega cilja. Študenti morajo vedeti, da bodo dosegli več, če bodo delali skupaj. Naloge znotraj skupine si razdelijo glede na zmožnosti in zanimanje. Pomembno je spremljati uspešnost vsakega posameznika. To sva poskušali doseči predvsem s pogovori »v živo« in vprašanji, s katerimi sva lahko sproti opazovali in preverjali, ali vsi opravljajo svoje naloge in sodelujejo. Skupine so delovale avtonomno, člani so si delili znanje in se osebno spodbujali. S tem se je ustvarjala kohezivnost skupine ter krepila osebna odgovornost do drugih in do cilja, ki ga morajo skupaj doseči.

\section{Neposredna interakcija (delo v skupinah)}

Ta značilnost sodelovalnega učenja se navezuje na vse druge. Najboljše je, da sodelovanje poteka iz oči v oči. Neposredna in tudi pozitivna interakcija pomeni, da posamezniki drug drugemu pomagajo, dajejo in sprejemajo informacije, prediskutirajo razmišljanja, predloge, ideje in rešitve, saj lahko tako pridejo do kakovostnejše odločitve in globljega vpogleda v obravnavane probleme, vplivajo drug na drugega, so motivirani za delo za skupno dobro, manj je tesnobe in stresa, delajo z zaupanjem (Johnson, Johnson 2017: 7).

Š4: V trenutku, ko si predan tekstu, ne vidiš kakšnih podrobnosti. Potem ko se oddaljiš, vidiš, da je dober izdelek, s tem se gradimo in se naučimo. Vidiš, da je dober tekst, da smo lahko ponosni. Ne glede na to, čigava ideja je, ustvari celoto.

Vsaka pravljica, ki so jo prevajali, je imela nekaj skupnih značilnosti z drugimi, skoraj vse so se na primer ukvarjale z okoljsko problematiko, v večini so nastopale živali, vsebovale so značilnosti paragvajske družbe, kulture, zgodovine ali univerzalne literarne tradicije. Zato sta bila potrebna usklajevanje in konsenz na celostni ravni antologije. Ta vprašanja so sodelujoči reševali v argumentirani razpravi ali pa so študenti, ki so raziskali določeno temo, na primer zgodovinski dogodek, o tem poučili kolege. »V razpravah študenti konstruirajo nove kognitivne strukture ali dostopajo do že obstoječih, da pridobijo nove informacije in izkušnje« (Johnson, Johnson, 2018: 68).

Š5: Vsak je sam prevedel pravljico, nato je prevod združil s kolegovim. Že takrat vidiš, da ima kolega drugačen pogled na en stavek, eno besedo, na primer, ali razbijemo dolg stavek na manjše dele; v štiricah so bili spet dodatni pogledi, mentorici spet drug pogled. Imeli smo možnost, da ostane naša rešitev. Na primer pri »brundati/mrmrati melodijo« je ostala naša rešitev, čeprav sta bili mentorici drugega mnenja. Na koncu vidiš, koliko se je prvotno besedilo spremenilo. 


\section{Socialne veščine}

Pri tovrstni učni praksi se študenti učijo socialnih veščin in jih razvijajo: vodenje, reševanje problemov, komunikacija, sprejemanje odločitev, ustvarjanje dobrega in zaupanja vrednega vzdušja, se pohvalijo, si pomagajo.

Š6: Zahteven projekt, si nismo predstavljali, v kaki meri in kaj vse je potrebno, da nastane tak prevod. Pozitivno bi izpostavila, poleg tega, da smo se ogromno naučili, da sta bili mentorici zelo potrpežljivi in so bili vsi komentarji, ne samo njuni, tudi od kolegov, konstruktivni, da smo se med seboj precej povezali. Jaz Urške nisem prej poznala, sva se spoznali in ostajava v kontaktu. Morda ta kolektivni duh.

\section{Skupinska evalvacija}

Analizo in evalvacijo dela smo opravljali sproti, s pogovorom in razpravo. Ugotovitve smo podajali tudi na že omenjenih predstavitvah projekta in produkta - knjige - na promocijskih dogodkih. Formalno so vsi študenti skladno z zasnovo in rezultatom projekta - prevod so podpisali vsi skupaj, ne vsaka dvojica »svojo« pravljico - na koncu prejeli isto (odlično) oceno za opravljeno nalogo.

Nalogo, ki smo si jo zadali v projektu prevajanja paragvajskih pravljic $\mathrm{v}$ slovenščino v okviru predmeta Prevajanje, smo uspešno opravili. Prispevek, v katerem sta opisana način in postopek dela s perspektive različnih oblik sodelovalnega učenja pri prevajanju, se osredotoča na pet bistvenih značilnosti te metode, druge podrobnosti izvajanja procesa pa so predstavljene zgolj v strnjeni obliki. Pomembno je poudariti, da so bile uporabljane tudi druge učne metode, katerih osnova ali okvir je bila sodelovalna metoda. Lahko govorimo o blended learning, kombiniranem učenju, ki prepleta različne učne sloge (Aramendi Jauregui, Bujan Vidales, Garín Caseres, Vega Fuente 2014: 416), med drugim problemskega učenja, skupinskega in tudi individualnega dela. Razvijanje kompetenc ni dodajanje predmetov, temveč spreminjanje metode, načinov dela in didaktičnih pristopov.

Prednost projekta je bila, da je bil izveden na drugostopenjskem programu s študenti, za katere se predpostavlja, da so motivirani za usvajanje prevajalskih veščin in novega znanja in imajo že veliko predznanja. Poseben izziv sta bila številčnost skupine in sodelovanje dveh profesoric-mentoric. Bistveno je, da so študenti v interakciji razvijali veščine in se učili drug od drugega. Želeli smo zagotoviti večjo aktivno participacijo študentov, večjo odgovornost za lastno učenje, izkoristiti potenciale vsakega posameznika, ki je 
skupini prinesel svoje veščine, svoja znanja, svoje védenje in vrednote. To potrjujejo v ta prispevek vključena razmišljanja študentov in produkt procesa, pa tudi podatek, da se je po tej izkušnji sedem študentov odločilo sodelovati pri še enem projektu skupnega prevajanja (podnaslovitev dokumentarnega filma), ki so ga prav tako uspešno izvedli.

V prispevku sva opisali način dela z uporabo sodelovalne metode 'na daljavo', saj smo se morali prilagoditi zdravstvenim razmeram. To je bil prav tako svojevrsten izziv. Ocenjujeva, da se je metoda izkazala za učinkovito tudi v takšni obliki. Sodelujočim je celo dopuščala večjo časovno svobodo in fleksibilnost pri organizaciji srečanj. Tudi mentorici sva se lahko večkrat srečali s posamezno dvojico ali skupino študentov in tako smo sproti reševali zagate. Po drugi strani pa ima delo na daljavo veliko pomanjkljivosti, poleg povsem tehničnih predvsem umanjkanje stika v živo, ki bi omogočal pristnejšo razpravo.

Zavedava se, da v prispevku ne opisujeva prave empirične raziskave, temveč pilotski projekt, izkušnjo oz. primer dobre prakse, vendar meniva, da prinaša zanimive ugotovitve in možnosti za izboljšave in nadgradnjo (evalvacija bi na primer lahko bila bolj strukturirana in načrtovana, posamezne vloge sodelujočih bi lahko natančneje določili ipd.).

Spremembe v načinu dela zahtevajo spremembe celotnega izobraževalnega sistema. Le tako je mogoče graditi skupnost družbeno odgovornih posameznikov, ki so lahko dejavniki sprememb. Casanova (2010: 54-55) pravi:

Sodelovalno učenje s pozitivnimi učinki svojih metod poganja razvoj bioetičnih vrednot, kot so spoštovanje človekovega dostojanstva, strpnost, solidarnost in sodelovanje. Je sredstvo, ki je nedvomno pomembno za socialni razvoj študentov, njihovo samospoštovanje, osebno, družbeno in kulturno identiteto z njihovim okoljem in svetom, v katerem živijo in sodelujejo.

Ferreiro Gravié slikovito pravi, da je sodelovalno učenje (sodelovanje nasploh) "protistrup za neoliberalizem, ki podžiga individualizem in tekmovalnost med neenakimi«. Meni, da je problem sveta etične narave, zato je pomembno, da so metode sodelovalnega učenja dinamične, vključujoče in gradijo osebnost. Znanje je družbena dobrina in pomembno se je učiti v skupnosti, kar je tudi naravno, saj smo socialna bitja (Ferreiro Gravié, Espino Calderón 2001: 22-25).

Končujeva $\mathrm{z}$ besedami študentke, ki najbolje povzemajo udejanjanje sodelovalne metode $\mathrm{v}$ opisanem projektu.

Š8: Skupinsko prevajanje ... dejansko v praksi toliko različnih oseb ne bere za tabo. Najprej je bil to produkt dveh oseb, ki sta morali nenehno sklepati kompromise. Seveda je vsako prevajanje proces, se pili, vrača, v našem primeru pa je že začetna faza potekala $\mathrm{v}$ dialogu dveh oseb, kar je po eni strani zelo težko, zato ker je treba za vsak najmanjši detajl, še posebej pa za zelo subjektivne elemente, vedno priti do nekega kompromisa, ko ni več vprašanje pravilnosti, 
natančnosti, pač pa nekih osebnih preferenc. Ampak mislim, da tako besedilo ni nikoli slabše, kot če bi to počela ena sama oseba. V praksi si tega procesa ne moremo privoščiti, ker je zamuden, kot je zamuden demokratični proces. Zlasti je težko skupno prevajanje na področju, kjer bi oseba lahko imela največ svobode, si dala duška v umetniškem smislu (in to je zelo subjektivno), ker je predlogov veliko. Po drugi strani se iz take izkušnje veliko naučiš, več, kot če se lotiš sam. Razhajanj je ogromno, pri vsaki povedi. Treba je paziti na koherentnost besedila. Midve si nisva razdelili en del ena en del druga, ampak gre za preplet in en glas. Prav otroške zgodbe iz tega še vedno pozabljenega sveta [Paragvaja] ne pridejo na naše police. Pri tem projektu, kar je bilo najtežje, a kar nas tudi bogati, je skupinsko delo, še posebej v teh časih, ko je takšno delo oteženo in je prav prišlo v času izolacije, lahko smo bili v stalnem dialogu z drugimi. ${ }^{10}$

\section{BIBLIOGRAFIJA}

ABERŠEK, Boris/Andrej FLOGIE/Magdalena ŠVERC (ur.) (2015) Sodobno kognitivno izobraževanje in transdisciplinarni modeli učenja. Pedagoška strategija. Maribor: Fakulteta za naravoslovje in matematiko. http://arhiv.inovativna-sola.si/images/ Monografija/Monografija_SI.pdf.

ARAMENDI JAUREGUI, Pedro/Karmele BUJAN VIDALES/Segundo GARÍN CASERES/Amando VEGA FUENTE (2014) Estudio de caso y aprendizaje cooperativo en la universidad. Profesorado 18/1, 413-429.

AŽMAN, Tatjana/Mateja BREJC/Andrej KOREN (2014) Učenje učenja. Primeri metod za učitelje in šole. Maribor: Filozofska fakulteta Univerze v Mariboru. https://solazaravnatelje.si/ISBN/978-961-6637-61-9.pdf.

CASANOVA, Farid (2010) El aprendizaje colaborativo y los valores bioéticos en educación: opción entre globalización o mundialización. Colombiana de Bioética 5/2, 53-60. https://www.redalyc.org/pdf/1892/189218186005.pdf.

FERREIRO GRAVIÉ, Ramón/Margarita ESPINO CALDERÓN ([2000] 2001) El abc del aprendizaje colectivo. Trabajo en equipo para enseñar y aprender. México: Editorial Trillas.

FERREIRO GRAVIÉ, Ramón (2003) Estartegias didácticas del apendizaje cooperativo. El constructivismo social: una nueva forma de enseñar y aprender. Editorial Trillas. JACOBS, George (2004) Cooperative learning: theory, principles and techniques. (Paper presented at the First International Online Conference on Second and Foreign Language Teaching and Research.) https://eric.ed.gov/?id=ED573881.

10 Besedilo je transkripcija posnetka iz predstavitvenega prispevku Paragvjaske pravljice, ki ga je izvedla založba Malinc in je dostopen na njeni YouTube strani: https://www.youtube.com/watch? $\mathrm{v}=\mathrm{vT} 5 \mathrm{eCycVBoc} \& \mathrm{t}=38 \mathrm{~s} \& \mathrm{ab}$ channel=Zalo\%C5\%BEbaMalinc. 
JOHNSON, David W./Roger T. JOHNSON/Edythe J. HOLUBEC (1999) El aprendizaje cooperativo en el aula. (Prev. Gloria Vitale). Buenos Aires: Editorial Paidós. https:// www.ucm.es/data/cont/docs/1626-2019-03-15-JOHNSON\%20El\%20aprendizaje\%20cooperativo\%20en\%20el\%20aula.pdf.

JOHNSON, David W./Roger T. JOHNSON (2017) Cooperative learning (Ponencia plenaria), I Congreso internacional Innovación Educación, 22 y 23 de septiembre 2017, Zaragoza. https://2017.congresoinnovacion.educa.aragon.es/documents/48/David Johnson.pdf.

JOHNSON, David W./Roger T. JOHNSON (2018) Cooperative Learning: The Foundation for Active Learning. IntechOpen: https://www.researchgate.net/publication/330952938_Cooperative_Learning_The_Foundation_for_Active_Learning.

ROT VRHOVEC, Alenka (2015) Sodelovalne učne oblike pri jezikovnem delu pouka slovenščine v osnovni šoli. CEPS Journal 5/3, 156-181. https://www.cepsj.si/index. $\mathrm{php} / \mathrm{cepsj} /$ article/view/133/65.

SLAVIN, Robert (2013) Sodelovalno učenje: kaj naredi skupinsko delo uspešno? H. Dumont, D. Istance, F. Benavides (ur.), O naravi učenja: uporaba raziskav za navdih prakse. (Prev. Sonja Sentočnik et al.). Ljubljana: Zavod Republike Slovenije za šolstvo, 147-162.

Strokovna podlaga za sodelovalno učenje (angl. Cooperative learning) (2020), Maribor: Univerza v Mariboru. https://didakt.um.si/oprojektu/projektneaktivnosti/Documents/Osnutek\%20strokovne\%20podlage_Sodelovalno\%20ucenje_NELE.pdf.

TRATNIK, Alenka (2014) Prek sodelovalnega učenja do znanja in pozitivne učne klime. Didakta 24/176, 20-24. https://www.dlib.si/stream/URN:NBN:SI:docKY6EPJMD/16666e42-f8a2-4f30-8039-ef9b41a8a736/PDF.

POVZETEK

\section{SODELOVALNO UČENJE PRI POUKU PREVAJANJA NA PRIMERU ANTOLOGIJE PARAGVAJSKIH PRAVLJIC}

Prispevek predstavlja uspešen poskus uvedbe sodelovalnega učenja pri pouku prevajanja iz španščine v slovenščino na magistrskem programu Hispanistika na Filozofski fakulteti Univerze v Ljubljani. Na konkretnem primeru ponazarja prenos glavnih teoretičnih izhodišč omenjene metode na specifično skupino - 21 študentov pri predmetu Prevajanje - in nalogo oziroma cilj učenja prevod antologije paragvajskih pravljic in njegov izid v knjižni obliki.

Avtorici sledita sodobnim teorijam in metodologijam sodelovalnega učenja, ki poleg kognitivnih procesov upošteva čustva in motivacijo, gradi socialne kompetence, spodbuja aktivno udeležbo učečih se, njihovo interakcijo in ustvarjanje novih znanj. Pri predstavitvi obravnavanega primera se osredotočita na pet bistvenih značilnosti te metode (pozitivna soodvisnost, individualna in 
skupinska odgovornost, spodbujanje neposredne interakcije, socialne veščine in skupinska evalvacija) in z opisom dela, analizo procesa in ugotovitvami, ki temeljijo na praktičnem delu, dokažeta, da jim izvedeni projekt $v$ celoti sledi in jih hkrati povezuje $z$ drugimi, bolj tradicionalnimi učnimi metodami. Pri tem poudarita in nazorno ilustrirata dinamiko krepitve sodelovalnega vzdušja med prevajanjem, sprva v dvojicah in manjših skupinah ter nato v skupini vseh udeleženih. Ugotavljata, da so k dosegi cilja največ prispevali pozitivna soodvisnost, povezanost in enakovreden odnos med učečimi se, sodelovalno skupino in učiteljem. Opozorita na posebno vlogo učitelja, ki naj ustvari razmere za sodelovanje, nato opazuje in posreduje le, kadar je to nujno, sicer pa spodbuja avtonomijo posameznikov in skupin(e). Izkušnjo sodelovalnega učenja ocenjujeta kot primer dobre prakse, ki pozitivno vpliva ne le neposredno na učenje konkretnih vsebin in spretnosti, temveč na življenje učečih se na vseh družbenih ravneh.

Ključne besede: sodelovalno učenje, prevajanje, didaktika prevajanja, španščina

\section{ABSTRACT}

\section{COOPERATIVE LEARNING IN TEACHING OF TRANSLATION USING THE EXAM- PLE OF AN ANTHOLOGY OF PARAGUAYAN FAIRY TALES}

The paper presents a successful attempt to introduce cooperative learning in the teaching of translation from Spanish into Slovenian in the master's programme in Hispanic Studies at the Faculty of Arts, University of Ljubljana. The concrete example illustrates the transfer of the main theoretical starting points of this method to a specific group - 21 students taking the subject Translation - and the task or goal of learning, the translation of an anthology of Paraguayan fairy tales and its publication in book form.

The authors follow modern theories and methodologies of cooperative learning, which, in addition to cognitive processes, take into account emotions and motivation, build social competencies, encourage the active participation of learners, their interaction and the creation of new knowledge. In presenting the case, they focus on five essential features of this method (positive interdependence, individual and group responsibility, promoting direct interaction, social skills and group evaluation) and demonstrate that by describing the work, analysing the process and making findings based on practical work, the implemented project fully expresses these features, and at the same time connects them with other, more traditional teaching methods. In doing so, they emphasize and clearly illustrate the dynamics of strengthening the collaborative atmosphere during translation, first in pairs and small groups and then in the group of all participants. They find that the positive interdependence, connections and equal relationships among students, the collaborative group and the teacher contributed the most to the achievement of the goal. They draw attention to the special role of the teacher, who must create the conditions for participation, then observe and intervene only when necessary, otherwise working to promote the autonomy of 
individuals and group(s). The authors assess the experience of cooperative learning as an example of good practice that has a direct positive impact not only on learning concrete content and skills, but on life at all levels of society.

Keywords: cooperative learning, translation, translation didactics, Spanish 